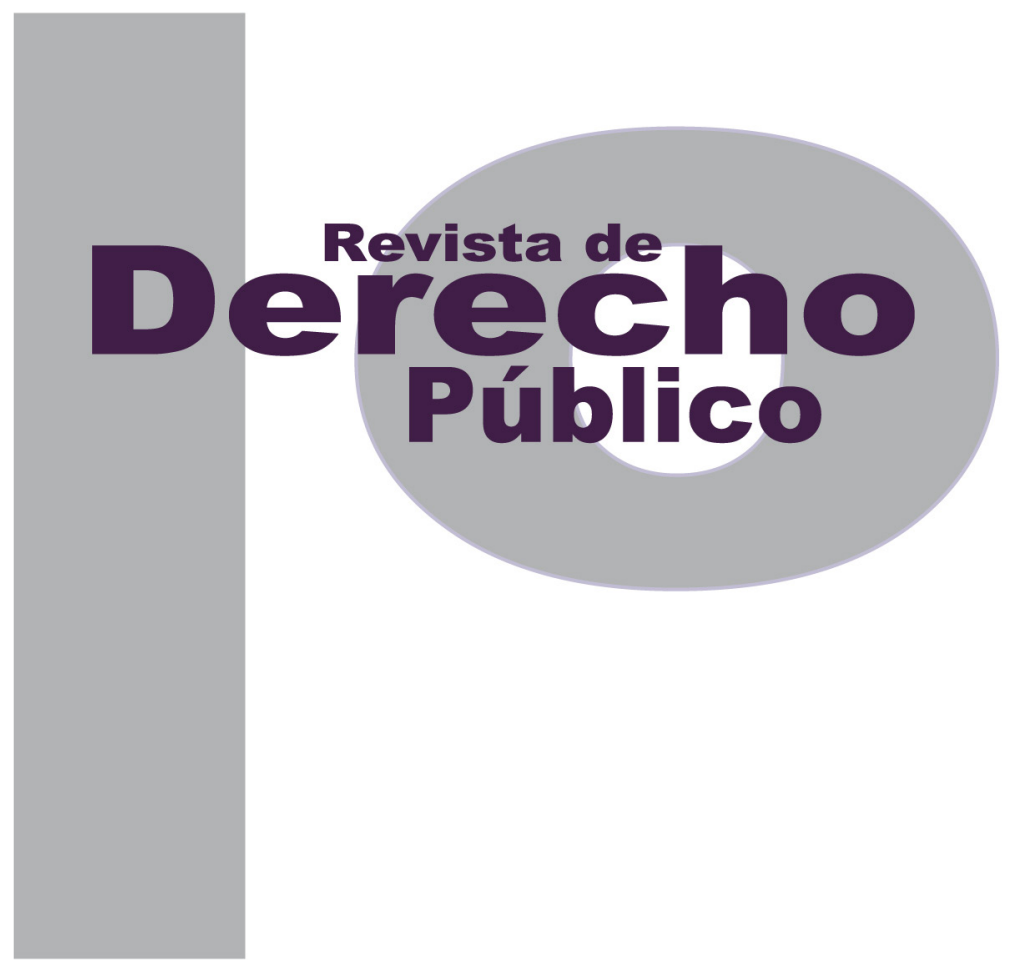

LA EMPRESA PÚBLICA EN LA PRESTACIÓN DE SERVICIOS PÚBLICOS DOMICILIARIOS EN COLOMBIA. UNA APROXIMACIÓN A SU RÉGIMEN CONTRACTUAL GENERAL

DAVID ANDRÉS SERRANo SALOMÓN

Artículo de reflexión

DOI: http://dx.doi.org/10.15425/redepub.36.2016.15

Universidad de los Andes

Facultad de Derecho

Rev. derecho publico No. 36

enero - junio de 2016. e-ISSN 1909-7778 


\title{
La empresa pública en la prestación de servicios públicos domiciliarios en Colombia. Una aproximación a su régimen contractual general
}

\section{Resumen}

El objetivo principal del presente trabajo es contrastar el régimen contractual de las empresas públicas encargadas de prestar servicios públicos domiciliarios con el discurso de la igualdad y la libre competencia que pregonan los servicios públicos liberalizados. En tal sentido, se aborda de manera breve la transformación que esta actividad prestacional ha experimentado, para luego entrar a registrar la evolución que ha tenido que surcar la contratación por parte de dichas entidades. Como resultado de lo anterior, se concluye que por más que se intente unificar el régimen jurídico de los operadores públicos y privados, en especial el de su ámbito contractual, lo cierto es que aquellos siguen presentando una fuerte dosis de derecho público como consecuencia de su inexorable subsunción a la organización y actividades de la administración pública.

Palabras claves: empresa pública, servicios públicos domiciliarios, liberalización, régimen contractual, libertad económica, derecho privado, principios de la función administrativa.

\section{An overview of the contractual regulation of public corporations that provide domiciliary pu- blic services in Colombia}

\begin{abstract}
This paper compares the contractual regime of those public corporations that provide domiciliary public services with the discourse of equality and free enterprise promoted by liberalized public services. An overview of the transformation that such provision has experienced is proposed followed by the evolution that the contractual regime of such entities has endured. It is argued that although regime unification between public and private operators has been tried, the former are still regulated mainly through public law given their inevitable subsumption to the organization and activities of public administration.
\end{abstract}

Key words: Public corporations; domiciliary public services; liberalization; contractual regime; free enterprise; private law; principles of the administrative function.

\section{A empresa pública na prestação de serviços públicos domiciliários na Colômbia. Uma aproxi- mação a seu regime contratual geral}

\section{Resumo}

O principal objetivo do presente trabalho é contrastar o regime contratual das empresas públicas encarregadas de prestar serviços públicos domiciliários com o discurso da igualdade e da libre concorrência que pregoam os serviços públicos liberalizados. Em tal sentido, se aborda de maneira breve a transformação que esta atividade de prestação tem experimentado, para depois entrar a registrar a evolução que tem tido que surcar a contratação por parte de ditas entidades. Como resultado do anterior, se conclui que por mais que se tente unificar o regime jurídico dos operadores públicos e privados, em especial o de seu âmbito contratual, o certo é que aqueles seguem apresentando uma forte dose de direito público como consequência de sua inexorável subsunção à organização e atividades da administração pública.

Palavras-chaves: empresa pública, serviços públicos domiciliários, liberalização, regime contratual, liberdade econômica, direito privado, princípios da função administrativa. 


\title{
La empresa pública en la prestación de servicios públicos domiciliarios en Colombia. Una aproximación a su régimen contractual general ${ }^{*}$
}

\author{
DAVID ANDRÉS SERRANO SALOMÓN**
}

\begin{abstract}
SUMARIO
Introducción - I. LA EMPRESA PÚBLICA Y EL SERVICIO PÚBLICO - A. Breve reseña de los servicios públicos económicos B. La empresa pública en la prestación de servicios públicos económicos - C. La empresa pública y los servicios públicos en la Constitución de 1991. Transformación del viejo modelo - II. LA CONTRATACIÓN DE LAS EMPRESAS PÚBLICAS EN LA GESTIÓN DE LOS SERVICIOS PÚBLICOS DOMICILIARIOS - A. La empresa pública en la Ley 142 de 1994 y el régimen de contratación a estudiar. Aspectos previos - B. Contratos que celebran las empresas públicas en el giro ordinario de su actividad - 1. Primera etapa. El primigenio artículo 31 de la Ley 142 de 1994 - 2. Segunda etapa. La reforma introducida por la Ley 689 de 2001 - 3. Tercera etapa. La relativa administrativización o publicización introducida por el artículo 13 de la Ley 1150 de 2007 - C. Algunas limitaciones a la autonomía de la voluntad privada en la contratación de las empresas públicas con respecto a la prestación de servicios públicos domiciliarios - III. CONCLUSIONES - Referencias.
\end{abstract}

* Cómo citar este artículo: Serrano Salomón, D. A. (Junio, 2016). La empresa pública en la prestación de servicios públicos domiciliarios en Colombia. Una aproximación a su régimen contractual general. Revista de Derecho Público, (36). Universidad de los Andes (Colombia). DOI: http://dx.doi.org/10.15425/redepub.36.2016.15

** Abogado de la Universidad de San Buenaventura de Cali. Especialista en Derecho Administrativo de la Universidad Pontificia Bolivariana de Medellín. Abogado externo de las Empresas Municipales de Cali EMCALI EICE -ESP. Correo: davidss89@hotmail.com. 
Introducción

A partir de la Constitución Política de 1991 se produjo una fuerte imbricación entre empresa pública y servicios públicos domiciliarios. En efecto, la norma fundamental estableció, como uno de sus puntos en materia de servicios públicos domiciliarios, la privatización y liberalización de dicha actividad, lo que conllevó la transformación del clásico modelo monopólico por uno nuevo sobre los cauces de la libertad económica. Esta circunstancia implicó, indefectiblemente, que el Estado, para participar de dicha actividad, se convirtiera en un empresario, adoptando de esta suerte las técnicas propias de los particulares, toda vez que ahora se encuentra en concurrencia con estos.

Las tesis de la igualdad y la libre competencia demandan de los operadores públicos y privados unas mismas reglas de juego a la hora de competir. Ello se debe reflejar en un régimen jurídico que, en la medida de lo posible, sea unificado para todos los agentes tanto en su estructura organizacional como en su actividad ordinaria empresarial.

La Ley 142 de 1994 no solo discriminó los agentes públicos de los privados, sino que también la misma evolución de su régimen jurídico terminó por diferenciar una de las actividades que con mayor calado impactan en el quehacer empresarial, esto es, su régimen de contratación.

La anterior es la reflexión que, precisamente, el presente trabajo pretende transmitir. Para tales efectos se aborda, en primer lugar, la transformación que han experimentado los servicios públicos domiciliarios como servicios públicos de carácter económico, de cuyo registro se sacará a relucir el discurso que tal evolución proyecta a la hora que el Estado empresario pretenda participar en dicha actividad. En segundo lugar, y como corolario de lo precedente, se explora el discurrir del régimen contractual general de la empresa pública en la prestación de servicios públicos domiciliarios, con el propósito de cotejar si hay coincidencia o no entre el discurso de la liberalización de los servicios públicos y el de la actividad negocial de la empresa pública en el ejercicio de los aludidos servicios prestacionales.

Como presupuesto de la anterior contrastación, se abordan algunos puntos relativos a cómo los principios de la función administrativa en la contratación de las empresas públicas terminan por dosificar el espíritu del derecho civil y comercial, y, con ello, al pilar fundamental que las hace posibles: la autonomía de la voluntad privada.

\section{LA EMPRESA PÚBLICA Y EL SERVICIO PÚBLICO}

\section{A. Breve reseña de los servicios públicos económicos}

Hablar del servicio público es, de cierta manera, hacer una radiografía de lo que es el Estado moderno, la administración pública y la relación dialéctica Estado-sociedad. Es una no- 
ción dinámica cuyo devenir de base se halla en las transformaciones socioeconómicas y en las construcciones políticas e ideológicas que legitiman el proceso de expansión o retraimiento histórico de los fines del Estado.

El servicio público es, por demás, una noción polisémica y compleja: es comprensivo de las más variadas actividades, por lo que se los tiende a clasificar en soberanos, sociales y económicos; se cuestiona sobre su forma, esto es, sobre si dicha actividad es un medio, solo una técnica más, o si es, antes bien, una proyección teleológica al margen del modelo de gestión que adopte; se discute sobre su realidad ontológica, en cuanto a si existen servicios públicos por esencia, o si son, por el contrario, una realidad contingente derivada de una decisión política del legislador primario o secundario; se los escinde cronológicamente en servicios públicos tradicionales y nuevos; y, finalmente, se debate sobre su naturaleza, es decir, si son función administrativa, una actividad económica más o una categoría autónoma.

Particularmente, para el derecho administrativo, la relación con el servicio público es especial. Históricamente lo ha acompañado desde sus comienzos y lo atraviesa en toda su evolución; primero, como criterio para dilucidar la problemática del reparto de competencias jurisdiccionales, y segundo, como expresión mis- ma de la función administrativa, convirtiéndose en el criterio legitimador y absoluto de esta disciplina jurídica ${ }^{1}$ gracias a la consolidación teórica que desarrolló la Escuela de Burdeos. ${ }^{2}$

El proceso de construcción y deconstrucción de la noción de servicio público ha llegado a tal punto que se afirma que esta categoría, tal y como se ha conocido tradicionalmente, ha fenecido. Que cumplió ya su misión, por lo que es inútil empeñarse en embalsamarlo. Que las realidades de base y de modelo de Estado han sufrido tal transformación, que han provocado, necesariamente, su revisión conceptual (Ariño Ortiz, 2003, p. 585).

Este es, pues, el caso, en particular, de los denominados servicios públicos económicos, cuya mutación se ha proyectado no tanto en su aspecto teleológico sino en su modelo de gestión, punto que me interesa reseñar.

Ciertamente, este tipo de servicios públicos, que surgen en virtud de la revolución industrial, trajo aparejada la extensión de la actividad estatal trascendiendo el angosto margen de acción del Estado decimonónico. El progreso técnico que conllevó esta revolución supuso la aparición de nuevas actividades (ferrocarriles, gas, electricidad, teléfono, transportes por carretera) que exigían una positiva intervención del Estado en el establecimiento de su pres-

1. Al respecto, Gastón Jezé (1948) afirmaba, de manera contundente, en su obra introductoria: "El derecho administrativo es el conjunto de reglas relativas a los servicios públicos. Todo país civilizado tiene servicios públicos, y para regular el funcionamiento de estos servicios existen necesariamente reglas jurídicas especiales. Se puede, pues, afirmar que en todo país donde se haya alcanzado la noción de servicio público (...) existe derecho administrativo" (p. 1).

2. Sobre el particular puede verse a Montaña Plata (2005). 
tación a través de la planificación y dirección (Ariño Ortiz, 2003, p. 522).

Primeramente, la gestión de estas prestaciones se desarrolló por medio de la figura de la concesión; fórmula ideal que hacía compatibles las ideas liberales -que no soportaban la intervención directa del Estado en asuntos ajenos a la reglamentación y al ejercicio del poder coercitivo- con la necesidad de afrontar la organización de estos servicios ineludibles, lo cual permitía al Estado dirigirlos sin gestionarlos (Garrido Falla, 1994). Posteriormente, estas prestaciones fueron asumidas directamente por la administración pública como fruto de la reversión de ciertas concesiones, por la caducidad o el rescate de estas (Ariño Ortiz, 2003, p. 291).

En un principio, el título de intervención sobre estas actividades reposaba en el uso del dominio público; luego, descansó en la simple declaración formal de un sector como público -"acto de publicatio"-. De esta manera, la actividad así declarada quedaba incorporada en el quehacer del Estado, y, por lo tanto, proscrita de la iniciativa privada, adquiriendo el carácter de monopolio público -"exclusividad regalística"-(Ariño Ortiz, 2003, pp. 520-524).

De esta suerte, la asunción de servicios públicos por parte del Estado sin más limitación que la mera declaración formal de la ley no era más que la prueba fehaciente de la transmutación de valores. El ensanchamiento de los fines del Estado como consecuencia de la expansión de los servicios públicos se desarrolló en la medida en que irrumpieron las ideas del Estado social y se volatizaron los dogmas liberales. ${ }^{3}$

Fue en este escenario, por lo pronto, donde se acentuó la correlación entre servicio público y derecho administrativo, en tanto que las manifestaciones de este subsistema jurídico solamente se entendían en función de aquel. Así, como lo expone Montaña Plata (2005, p. 147), se consideraban “agentes públicos (funcionarios) las personas empleadas en los distintos servicios públicos; el 'dominio público', estará constituido por los bienes involucrados en los servicios públicos; y 'trabajo público' será aquel efectuado en desarrollo de un servicio público", siendo también, dicha actividad prestacional, el único "criterio de atribución de jurisdicción administrativa”. De modo que solo

en los casos de la concesión, y sin perjuicio de la relación administrativa que une al concesionario con la Administración, entraba en juego el Derecho privado aplicable al concesionario en sus relaciones con los usuarios y terceros, así como la Jurisdicción civil para la resolución de los conflictos. (Parada, 2007, p. 393).

Sin embargo, fue en virtud de la denominada crisis del Estado social ${ }^{4}$-o más bien, la crisis de una forma histórica de entender el Estado

3. Sobre la relación existente entre Estado social y servicio público puede verse: Montaña Plata (2010, p. 143).

4. Sobre el particular pueden verse: Restrepo Medina (2010) y Orozco Guerrero (2009). 
social ${ }^{5}$ - por un lado, y la exacerbación de las ideas de la globalización informada por las tesis neoliberales, por el otro, aunados a un progresivo poder económico en manos de la sociedad civil y un acelerado proceso de crecimiento e innovación tecnológica (Fernández Rodríguez, 1999), lo que ocasionó, indefectiblemente, una profunda transformación del modelo tradicional de gestión directa del servicio público, redirigiendo la mirada hacia los particulares, quienes entraron a satisfacer de manera directa las exigencias sociales de la población en un ambiente de libertad económica.

Es en dicho contexto donde el servicio público se replantea en varios frentes, sobre todo, el relativo al modelo de gestión basado en la planificación, dirección y gestión en manos de la administración pública. Así, como lo expone Gaspar Ariño:

Frente al modelo de gestión monopólica y pública de los servicios, se propugna [por un] modelo de gestión plural y privada que devuelva al ciudadano la libertad de elegir. Frente a la gestión administrativa-burocrática, hoy se postula la actuación a través de empresas privadas y organizaciones no gubernamentales, capaces de asumir con mayor flexibilidad, mayor eficacia y mayor calidad la satisfacción de las necesidades sociales. (2003, pp. 153-154).

En suma, los servicios públicos se vieron permeados por las ideas de privatización y liberalización. “Ya no más servicios públicos, sino actividades privadas reguladas, es la nueva consigna" (Parada, 2007, p. 380); ${ }^{6}$ o si se quiere, servicios económicos de interés general. ${ }^{7}$ El nuevo modelo de gestión será la regulación para la competencia. ${ }^{8}$

Así las cosas, la actual gestión de los servicios públicos por los cauces del mercado demandaba que esta actividad prestacional estuviese dinamizada, como regla general, por los tro-

5. Comparto las observaciones de Fernández-Miranda Campoamor (2003, p. 147), quien al manifestarse sobre la supuesta crisis del Estado social afirmaba que “lo que está en crisis, no es ni el Estado social de derecho, como principio jurídico constitucional, ni el Estado de bienestar como fin a perseguir, sino tan solo o, si se prefiere, nada menos que, una forma histórica del Estado de bienestar". Es decir, lo que está o entró en crisis es el empleo de ciertos modelos de gestión para la consecución de los fines del Estado social, mas no los valores o propósitos que inspiran a este modelo de Estado.

6. Algunos autores, en virtud del nuevo modelo, han querido remplazar la noción de servicio público por el concepto de regulación económica. Cassagne (2002) es crítico de tal postura. Él considera, por el contrario, que el servicio público a pesar de su nueva dinámica, es una institución típica y definida, mientras que la regulación constituye una función o actividad englobada en el poder de policía, por lo que no se puede confundir la regulación con la institución que regula.

7. Los servicios económicos de interés general constituyen un supraconcepto adoptado en el marco de la Unión Europea para cobijar tanto a los servicios públicos tradicionales (publicatio), como aquellas fórmulas alternativas donde se responde a las mismas actividades por la vía de la regulación. Para tal efecto puede verse: Fernández (1999).

8. Este modelo propugna, como lo manifiesta Gaspar Ariño (2003), por un sistema abierto y competitivo, que dé lugar a una gestión plural y privada a través de los troqueles del mercado, que facilite el acceso a este y que dé paso a la libertad de inversión y de contratación. La regulación para la competencia es, como su mismo nombre lo indica, una regulación que propenda por la promoción de la competencia allí donde esta sea posible, que recree el mercado cuando esta sea potencialmente competitiva, y que la defienda cuando sea vea en peligro (pp. 585-607). 
queles del derecho común. La privatización de estos dio lugar a un cambio en las formas clásicas de intervención estatal, y, con ello, a un replanteamiento del lugar en que debe situarse la administración pública. ${ }^{9}$ De esta suerte, el Estado pasó de ser un agente prestador de servicios públicos a un Estado regulador o garante de dichas actividades. ${ }^{10}$

Bajo el orden de ideas precedentes se podría concluir que este modelo - hasta ahora- empezó con los particulares y terminó de igual modo con ellos; primero, como concesionario, luego bajo su propia iniciativa económica. E cambio, en definitiva, se ha suscitado en su titularidad, en el régimen jurídico que la informa y en la técnica de intervención estatal. Esta transformación, tal como se adujo en un principio, no es más que el resultado de los cambios socioeconómicos, políticos, ideológicos y tecnológicos que la soportan; de ahí el dinamismo del servicio público.

\section{B. La empresa pública en la prestación de servicios públicos económicos}

Sea lo primero decir que la empresa pública, como aproximación conceptual desde la disci- plina del derecho, es un tema que se encuentra ya depurado. El impulso de esta institución, a partir, sobre todo, de la segunda mitad del siglo pasado por parte del Estado, ${ }^{11}$ animó a la doctrina jurídico-administrativa a decantar, de manera prolija, alguna acepción sobre el particular. La motivación que llevó a comprender dicho fenómeno era clara. Se trataba se encajar a la empresa pública dentro de la organización y actividad administrativa.

Ciertamente, la empresa pública trajo aparejada la construcción de una nueva categoría orgánica y material que el derecho administrativo clásico no suministraba. Así, desde el primer punto de vista, apareció el establecimiento público industrial y comercial, motivando, en gran parte, la crisis del concepto de establecimiento público como servicio público personalizado (Garrido Falla, 1994); y desde el segundo punto de vista apareció la categoría denominada gestión económica, yuxtaponiéndose a las clásicas acepciones de policía, fomento y servicio público (Villar Palasí, 1950).

Ahora bien, en cuanto respecta a la empresa pública como categoría conceptual, es de anotar que son varios los criterios que se pueden destacar; entre ellos, el relativo a su forma

9. Sobre el particular, Restrepo Medina (2007).

10. En nuestros días el Estado regulador es, como lo señala Carro Fernández-Valmayor (2014), "un Estado garante o garantista (Gewährleistungsstaat), esto es, un Estado que, al haber dejado de ser, en gran medida, un Estado gestor o prestacional (Leistungsstaat), debe garantizar, mediante las oportunas medidas normativas y organizativas, los servicios de carácter esencial que han pasado a ser gestionados por sujetos privados, procurando, a la vez, que la actividad de dichos sujetos se lleve a cabo con los imprescindibles niveles de objetividad, accesibilidad y calidad" (p. 35).

11. Sobre el trasegar de la empresa pública puede verse: Brewer Carías (1967) y Garrido Falla (1991). 
jurídica, ${ }^{12}$ origen ${ }^{13}$ y finalidad. ${ }^{14}$ En todo caso, parece existir acuerdo general en la doctrina que lo que define a una empresa como pública es que el Estado tenga la capacidad de dirección, condicionamiento permanente o una influencia dominante sobre la misma debido a la titularidad de su propiedad, a su participación financiera o en razón de las normas que la rigen. ${ }^{15}$

En atención a lo anterior, podemos definir a la empresa pública como aquella organización jurídico-económica dotada comúnmente de personería jurídica, creada directa o indirectamente por el Estado, para la realización de actividades industriales y comerciales, así como para la prestación de servicios públicos de igual naturaleza, cuya dirección y control corresponde al sector público, y que, por regla general, se rige por el derecho común.

Pues bien, partiendo entonces de la premisa de que los servicios públicos se despliegan en un ambiente de libertad económica y libre competencia como corolario de su liberalización, ${ }^{16}$ lo más común es que cuando el Estado pretenda participar de dicha actividad la realice a través de sus empresas públicas; prestación que deberá ejercerse en condiciones de igualdad, esto es, sin ningún tipo de privilegios o cargas injustificadas.

La razón anterior es clara. La idea es que el discurrir de la empresa pública en el mercado no deforme la competencia. Como lo señala Correa Henao (2008), el Estado, en

su participación en el mercado debe operar en condiciones de igualdad o de concurrencia económica respecto de las empresas privadas que actúen en el mercado o que pretendan constituirse para tal efecto, observación que por lo pronto se entiende solo en términos de que la iniciativa pública no puede significar exclusión o restricción del campo de acción económica de la concurrencia o privilegios sobre el mercado de ninguna especie. A ese respecto se ha entendido que funciona como una empresa más. (P. 189).

Por ello se puede concluir que si la administración pública va a incursionar en la actividad

12. Las empresas públicas pueden estar dotadas o no de personería jurídica. Sin embargo, se ha sostenido que la realidad pública empresarial propiamente dicha se inserta en la estructura administrativa del Estado a través de las formas societarias mercantiles, y en especial, por conducto de la sociedad anónima, es decir, órganos con personería jurídica. Al respecto, Bassols Coma (1977).

13. Las empresas públicas tienen su origen en el Estado, ya sea de manera directa, esto es, a través de ley o acto administrativo, o indirecta, vale decir, por medio de un acuerdo societario previa autorización de una norma jurídica.

14. La empresa pública debe estar al servicio de un interés público o general.

15. Sobre el particular, Ruiz (1982); también, Rivero Ysern (1978).

16. Entiéndase por liberalización la “desmonopolización de actividades que antes gozaban para el Estado del privilegio de la publicatio. Ello permite la prestación concurrente de estas a los particulares. Es, en otros términos, la posibilidad que se les otorga a los particulares de desarrollar de manera concurrente con el Estado actividades de servicio público" (Restrepo Medina, 2010, pp. 54-55). 
empresarial en concurrencia con los particulares, es de suyo entender, en principio, que la empresa pública deba inscribirse "necesariamente en el mercado y en las exigencias que le son propias" (Correa Henao, 2008, p. 398), que entre otras cosas significa que debe regirse por el derecho privado o común.

Así, se dice que la observancia del derecho privado por parte de la empresa pública no solo sirve como acicate para enervar cualquier tipo de privilegio, sino también en provecho de su propia sobrevivencia en el mercado. En ese sentido, por ejemplo, se justifica este régimen en materia de contratación en la "necesidad de dotar a tales entidades de la versatilidad y capacidad de acción inmediata que les permita competir en igualdad de condiciones con las entidades del sector privado" (CConst., C-722 de 2007 , C. Vargas); aspecto que no se podría desarrollar si tuviese que obedecer los engorrosos trámites que regula el derecho público.

\section{La empresa pública y los servicios públicos en la Constitución de 1991. Transformación del viejo modelo}

La Constitución Política de 1991 previó expresamente a las empresas públicas. Ellas son mencionadas a propósito del reconocimiento de la incitativa economía pública (arts. 334 y 365), la cual se materializa a través de las atribuciones del legislador (art. 150.7) y de las Asambleas Departamentales (art. 300.7) y Concejos Distritales y Municipales (313.6), en su ámbito respectivo, en torno a la configuración y desarrollo de la estructura de la administración pública (nacional, departamental o municipal) para la creación o autorización de empresas industriales y comercial del Estado y sociedades de economía mixta. ${ }^{17}$

Del mismo modo, los servicios públicos fueron objeto de constitucionalización. La Constitución del 91, sin ser ajena a los cambios suscitados en el derecho comparado, produjo la superación del clásico modelo de carácter monopólico y público, implementando, a su vez, uno nuevo sobre los cauces de la libertad económica.

La constitucionalización del servicio público, por demás, no obedeció a la mera liberalidad de quienes atisbaron la Asamblea Nacional Constituyente, sino que, por el contrario, surgió en el marco de una especial preocupación. Fue, en últimas, la crisis por la que atravesaba lo que ameritó que esta temática se haya jerarquizado en el máximo nivel normativo a fin de proyectar su verdadera dimensión económica y social. ${ }^{18}$

17. Se subraya que la empresa pública no solo se cristaliza en esta clase de entidades. La Corte Constitucional ha sido contundente en decir que la estructura de la administración pública es flexible, por lo que es perfectamente posible que el legislador pueda idear otra clase de organismos públicos no previstos expresamente en la Constitución (Sentencia C-736/2007, M. Monroy).

18. Sobre este debate en el seno de la Asamblea Nacional Constituyente puede verse: Gaceta Constitucional n.o 53,18 de abril de 1991, pp. 2 a 6. 
Así, merced al contenido general del artículo 365 Superior, el Estado como los particulares pueden concurrir en la prestación de servicios públicos, en tanto que cualquier persona o grupo de personas puede organizar una empresa de servicios públicos sin necesidad de un título habilitante en particular. ${ }^{19}$ Quiere ello significar que por expresa e inequívoca habilitación constitucional el Estado ha desmonopolizado la gestión de los servicios públicos a favor de la iniciativa privada, por lo que, en definitiva, fue voluntad del constituyente que esta actividad prestacional fuera objeto de privatización y liberalización.

En virtud de lo anterior, se desprende claramente que el constituyente reconoce la coiniciativa económica en la gestión de los servicios públicos; iniciativa que, por demás, no está sujeta al principio de subsidiariedad, habida cuenta que el sector estatal, como se acotó, puede, por decisión de las corporaciones públicas, participar en la creación o autorización de empresas públicas con independencia de que existan en el mercado empresas privadas encargadas de prestar dichas actividades económicas. Ello se desprende no solo del sentido del artículo 365 Superior ya citado, sino también del artículo 334 ibídem, que permite la intervención del Estado en la economía para materializar los múltiples propósitos y finalidades que dispone dicha norma. ${ }^{20}$

Esta coiniciativa económica solo se rompe -jurídicamente hablando- en el caso que se dé la hipótesis fraguada en el inciso segundo del artículo 365 constitucional, dado que según dicho precepto el Estado puede, mediante ley del Congreso, reservarse por razones de soberanía y de interés social determinadas actividades estratégicas o servicios públicos. Esta reserva que se desarrolla mediante ley formal, no es otra cosa que un vestigio de la vieja publicatio, en virtud de la cual, una vez la actividad se declaraba como pública, esta entraba al quehacer del Estado, sustrayéndola, de este modo, de la iniciativa privada.

Con todo, creo que tal disposición opera de manera excepcional. Esta tesis se fundamenta en las siguientes razones: 1) por el sistema de libre entrada o liberalización que significó los servicios públicos en la Constitución de 1991; 2) porque constituye una limitante intensa aunque legítima- de la libertad económica (art. 333), propiedad privada (art. 58) y acceso a la propiedad (art. 60) que pregona la Carta Política; 3) por el quorum calificado que debe presidir a dicha decisión (ley aprobada por la mayoría de los miembros de una y otra Cáma-

19. Que no sea necesario la obtención de un título habilitante para prestar servicios públicos se basa, según Palacios Mejía (1999), en "la estrategia de atracción de capital privado [que] se funda, ante todo, en el principio de "libertad de entrada", en virtud del cual se permite a cualquier grupo de personas organizar una empresa de servicios públicos y prestarlos sin permisos estatales especiales" (p. 174).

20. Para la Corte Constitucional (Sentencia C-150/2003, M. J. Cépeda), la intervención del Estado en la economía no constituye una mera facultad, sino, por el contrario, un imperativo constitucional a fin de cumplir los propósitos teleológicos que regenta el artículo 334 Superior. Ahora, aspecto contrario son los instrumentos para acometer tal intervención, la cual es objeto de libertad de configuración legislativa. Uno de tales instrumentos es la creación de empresas públicas. 
ra, por iniciativa gubernamental); y 4) porque debe fundarse en un principio de razón suficiente y no por mera liberalidad, esto es, por razones de soberanía o de interés social, atendiendo parámetros de proporcionalidad. ${ }^{21}$

Por último, resta advertir que si bien los servicios públicos - como actividad liberada- están sujetos a la garantía de la libertad económica (libertad de empresa y de competencia), ello no quiere significar que su complejo normativo se agote en dicho articulado. Una interpretación sistemática derivada del mismo artículo 333 constitucional y el contenido dogmático del texto fundamental permiten afirmar que esta actividad está plegada por ciertos límites, como son el bien común, la solidaridad, la igualdad (material) y los principios y deberes que informan al Estado social (Montaña Plata, 2003). De allí que los servicios públicos, como Io afirma Carlos Atehortúa (2008), no pueden ser confundidos con el ejercicio de las actividades económicas libres, que se someten al régimen ordinario de otros bienes y mercancías, cuyo eje medular descansa en la autonomía de la voluntad, sino que, por el contrario, están sometidos a un régimen jurídico especial que supone una intensa intervención del Estado en tanto que el núcleo de su teoría reposa en el principio de solidaridad.

Es, pues, en virtud del anterior cuadro normativo que autores como Bernal Pulido (2009) ad- vierten una ambivalencia constitucional entre el concepto de Estado social con la liberalización de los servicios públicos. Posturas que por estar siempre en conflicto deben ser resueltas con fundamento en el principio de proporcionalidad.

\section{LA CONTRATACIÓN DE LAS EMPRESAS PÚBLICAS EN LA GESTIÓN DE LOS SERVICIOS PÚBLICOS DOMICILIARIOS}

\section{A. La empresa pública en la Ley 142 de 1994 y el régimen de contratación a estudiar. Aspectos previos}

Los servicios públicos domiciliarios en Colombia siguieron, en gran parte, el trasegar de los servicios públicos de carácter económico esbozados precedentemente. En efecto, previo a la expedición de la Constitución de 1991, el modelo de gestión estaba organizado bajo la fórmula del Estado asistencialista, que se caracterizó por la asunción exclusiva de su prestación por parte del Estado, lo cual demandó, ciertamente, un "proceso de expansión orgánica estatal para dar mayor cobertura y eficiencia a la prestación de estos servicios" (Bernal Pulido, 2009, p. 181). Con la expedición de la Ley 142 de 1994 se puso a tono la nueva realidad constitucional, liberando a dichas actividades del monopolio estatal para dar cabida a la iniciativa privada.

21. Autores como Palacios Mejía (1999, pp. 51-52) niegan de manera rotunda la posibilidad de monopolios públicos en materia de servicios públicos. Para él, es una contradicción que el Constituyente haya previsto dicha posibilidad, pues no se explica cómo el propósito de una mayor cobertura y prestación eficiente en materia de servicios públicos -propósitos explícitos de la Carta Política- se pueda materializar en forma monopolística. 
Con todo, dicha ley, en armonía con el artículo 365 Superior, abrió la posibilidad de que el Estado pudiese concurrir junto con los particulares en la prestación de los servicios públicos domiciliarios a través de una forma institucional ya conocida. Se trata de la empresa públi$\mathrm{ca}$, que orgánicamente se tradujo en las empresas industriales y comerciales del Estado y en las empresas de servicios públicos oficiales y mixtas previstas en los artículos 17, 14.5 y 14.6 de la Ley 142 respectivamente. Empresas estas dos últimas que nuestro sistema jurídico ya conocía con el nombre de sociedades públicas y sociedades de economía mixta bajo la vigencia de los decretos 3130 de 1968 y 130 de 1976, pero que ahora ostentan naturaleza especial. $^{22}$

La Ley 142 de 1994, entonces, previó, en relación con la gestión económica directa del Estado, la creación de típicas empresas públicas, dotadas de personería jurídica, situadas en el sector descentralizado de la administración, en el que el Estado, los entes territoriales o las entidades descentralizadas, en razón del capital público absoluto o mayoritario del capital social, ostentan la capacidad de dirección, condicionamiento permanente o una influencia dominante sobre este.

Actividad de gestión directa del Estado que, por hallarse en un contexto de libertad de com- petencia, demanda, según el discurso de la liberalización, en la medida de lo posible, las mismas pautas o reglas de juego tanto para los operadores públicos como para los privados, y es capaz de soportar, en ese mismo sentido, un régimen jurídico también único (Montaña Plata, 2009, p. 164). Régimen jurídico similar que se debe reflejar, en particular, en su actividad ad extra, y en especial, en su régimen de contratación.

En tal virtud, se estudiará si el estatuto de contratación de las empresas públicas en la prestación de servicios públicos domiciliarios se encuentra, desde un punto de vista jurídico, en similares condiciones en que se halla la empresa privada. Estudio que se concentrará en las reglas generales que disciplinan los negocios jurídicos bilaterales que celebran estas empresas en el quehacer ordinario de su actividad, obviando, en tal sentido, a los otros regímenes a pesar de su relevancia sectorial. ${ }^{23}$

\section{B. Contratos que celebran las empresas públicas en el giro ordinario de su actividad}

El estudio del régimen contractual aplicable a las empresas públicas en la prestación de servicios públicos domiciliarios no ha estado libre

22. Sobre la naturaleza especial de estas empresas puede verse: Corte Constitucional (Sentencia C-736 de 2007, M. Monroy).

23. Como lo señala Atehortúa (2009), en el sector de los servicios públicos domiciliarios, cuando se hace referencia a su régimen de contratación, son cuatro los temas diferentes que normalmente comprende; ellos son: “1. Los contratos que se celebran con el fin de constituir las empresas de servicios públicos. // 2. Los contratos que celebran los prestadores estatales de 
de perplejidades. La imbricación intensa entre categorías de orden formal público (entidades de carácter estatal) con categorías de orden material privado (régimen jurídico común), aunada al trasegar jurídico por el que ha tenido que atravesar, han contribuido a crear ciertas dificultades sobre la manera en que se deben resolver los problemas relativos a la interpretación y aplicación de las normas de contratación que las rigen.

Dicho trasegar jurídico por el que ha tenido que atravesar el régimen de contratación en el sector de los servicios públicos domiciliarios se puede dividir básicamente en tres etapas, a saber: la primera, que surge de la expedición de la Ley 142 de 1994, en la que se asienta un doble régimen de contratación (público y privado) para las entidades estatales, que conllevó una serie de dificultades para dilucidar cuándo se gobernaba por uno u otro; la segunda, que nace en virtud de la reforma que introdujo la Ley 689 de 2001, en donde de manera categórica se afirma que las entidades estatales no se regirían por la Ley 80 de 1993 sino por el derecho común; y la tercera, que aparece a partir del artículo 13 de la Ley 1150 de 2007, con el que se introdujo una relativa administrativización o publicización del derecho privado que informa sobre la contratación de las empresas públicas.
Es de subrayar, por demás, que el análisis se realizará bajo el artículo 31 de la Ley 142 de 1994, que es la regla general aplicable a las entidades estatales. Entiéndase, a su turno, por entidades estatales en el sector de los servicios públicos domiciliarios, a las empresas industriales y comerciales del Estado y las empresas de servicios públicos domiciliarios oficiales y mixtas, ${ }^{24}$ merced a la remisión normativa prevista en el artículo 2 de la Ley 80 de 1993. Por lo tanto, las reflexiones a desarrollar se cristalizarán en torno a dichas empresas.

1. Primera etapa. El primigenio artículo 31 de la Ley 142 de 1994

Recién expedida la Ley 142 de 1994, el artículo 31 se remitió al parágrafo 1 del artículo 32 de la Ley 80 de $1993^{25}$ en materia de contratación para las entidades estatales; remisión que en el fondo implicaba una equiparación jurídica de todos los operadores al derecho privado, por lo menos tratándose del giro ordinario de su actividad, pero que, por la redacción a que se apelaba, pronto daría lugar a cierta perplejidad en relación con el alcance que a este tema se le debía dar en la práctica.

Sobre el alcance que dicha disposición normativa proyectaba sobre el régimen de contrata-

servicios públicos y su régimen especial. // 3. Los contratos que por sus características especiales son propios del sector de los servicios públicos domiciliarios. // 4. El contrato de condiciones uniformes que es el que rige las relaciones entre las empresas y sus usuarios" (p. 143).

24. En este último caso, siempre y cuando la participación pública sea superior al $50 \%$ del capital social.

25. El parágrafo $1^{\circ}$ del artículo 32 de la Ley 80 de 1993 establecía que el régimen de contratación de las entidades financieras de carácter estatal no es el de esta ley, sino el que rige las actividades propias de su objeto social. 
ción de las entidades estatales en el sector de los servicios públicos domiciliarios, Marín Cortés (2010), con especial sindéresis, manifestaba lo siguiente:

El artículo 31 dispuso que los contratos que celebren las empresas de servicios públicos domiciliarios "[...] que tengan por objeto la prestación de esos servicios se regirán por el parágrafo $1^{\circ}$ del artículo 32 de la Ley 80 de 1993 [...]" [cursivas fuera del texto], infiriéndose de aquí que los contratos que no tengan por objeto la prestación de tales servicios se seguirán rigiendo por la ley 80 de 1993. La norma así entendida, no dejaría de ser fuente de serias dificultades jurídicas prácticas, pues la discusión que podría surgir entre las empresas de servicios públicos domiciliarios y los órganos de control, acerca de cuáles contratos tienen por objeto la prestación de los servicios y cuáles no, era casi segura. No obstante, eso fue lo que dispuso el legislador, pese a que cause problemas. (Pp. 346-347).

En ese orden, comparto las ideas del autor citado, en el sentido que, en últimas, el artículo 31 de la Ley 142 lo que vino a establecer fue un "doble régimen de contratación que tendrían las empresas de servicios públicos domiciliarios" (p. 347). Pues, a propósito del giro ordinario de sus actividades, el régimen a aplicar no era más que el de derecho privado; por el contrario, si se trataba de actividades ajenas a las propias, el régimen era el de la Ley 80 de 1993. En todo caso, detrás de dicha bifurcación se podía valorar la intención del legislador, que no era otra que la de equiparar jurídicamente el régimen de contratación de los operadores públicos y privados en relación con aquellas actividades incursas en condiciones de competencia económica, al margen, pues, de las dificultades de interpretación práctica que esa intención legislativa aparejaba.

2. Segunda etapa. La reforma introducida por la Ley 689 de 2001

El legislador del año 2001, a través del artículo 3 de la Ley 689, vino a superar la ambigüedad que en otrora había establecido en relación con el régimen de contratación bifronte para las empresas públicas en el sector de los servicios públicos domiciliarios, al reformar el artículo 31 de la Ley 142 de 1994. Fue así como, de manera inequívoca, la Ley 689 prescribió que las entidades estatales que prestaran servicios públicos no estarían sujetas a las disposiciones del estatuto general de la contratación pública, salvo que la aludida ley dispusiera otra cosa.

Con ello quedaba claro que toda la contratación de las empresas públicas, independientemente de si se tratase de actividades regulares u ordinarias, quedaba sujeta a las disposiciones del derecho común. ${ }^{26}$ Ello implicaba, cla-

26. Lo anterior, claro está, sin perjuicio de las disposiciones excepcionales que prevé la misma Ley 142 de 1994, como son, entre otras, lo prescrito en el parágrafo del artículo 31, el numeral 1 del artículo 39 y el artículo 61. 
ramente, que todo lo relativo a las etapas de formación, ejecución, terminación y, de ser el caso, liquidación contractual, quedaba sometido a la disciplina y lógica propias del derecho civil y comercial. Lo cual se traduce, en palabras del profesor Carlos Atehortúa (2009), en las siguientes consecuencias que se transcriben in extenso:

1. La selección del contratista: no se requiere aplicar como procedimiento la licitación, ni la contratación directa a que se refieren la Ley 80 de 1993 y sus decretos reglamentarios (...).

2. Los elementos de existencia del contrato: las reglas relativas al perfeccionamiento de los contratos no son las contenidas en el artículo 41 de la ley 80 de 1993, sino que ellos se perfeccionan en general con la expresión válida del consentimiento por las partes y no requieren ponerse por escrito, salvo que la ley civil o comercial así lo demanden.

3. Los requisitos de validez del contrato: son los previstos en la legislación civil y comercial y, por lo tanto, las causales de nulidad son las propias de los contratos entre particulares y no las contenidas en la Ley 80 de 1993.

4. Los procedimientos: son los propios de la contratación entre particulares; por lo tanto, para su ejecución o en desarrollo de ella no se requiere el cumplimiento de solemnidades, aprobaciones o autorizaciones especiales.

5. Las cláusulas contractuales: son las propias de los contratos entre particulares; por lo tanto, salvo en los casos a que se refiere el artículo 31 de la ley, en estos contratos no deben pactarse cláusulas exorbitantes.

6. La ejecución del contrato: debe realizarse de conformidad a las reglas ordinarias y no según las administrativas; y

7. Lo relacionado con la terminación, ampliación y liquidación de los contratos: deben aplicarse las reglas propias del derecho común y no las del administrativo.

Estas reglas generales se aplican aun a las entidades oficiales que prestan servicios públicos con fundamento en lo establecido en el artículo 31 de la Ley 142 de 1994, modificado por el artículo 3. ${ }^{\circ}$ de la Ley 689 de 2001. (Pp. 417-418). [Cursivas añadidas].

Así entonces, con la reforma introducida por la Ley 689 de 2001, el derecho común se convirtió en la constante del régimen contractual de las empresas públicas, cumpliendo, de este modo, las exigencias económicas de la gestión de estos servicios, que no son otras que las exigencias de la libre competencia, vale decir, el imperio de unas mismas reglas de juego para los operadores públicos y privados en el mercado.

\section{Tercera etapa. La relativa administrativización o publicización introducida por el artículo 13 de la Ley 1150 de 2007}

Si bien es cierto que la participación de la empresa pública en el mercado demanda de ella 
la sujeción a las reglas del derecho privado como corolario de los principios de igualdad y libre competencia, no es menos cierto que por el solo hecho de ostentar el carácter de pública se inscribe, necesariamente, en los cuadros de la administración pública, y, con ella, en los principios que le son connaturales, que son los necesarios para contener la unidad del Estado.

En ese orden de ideas, se puede decir que la concurrencia de la empresa pública en el mercado exige, por lo menos, la mutilación de aquellas prerrogativas y privilegios inherentes al Estado, ya que ello iría en menoscabo de la empresa privada. ${ }^{27}$ Pero ello no significa que el discurso de la igualdad sirva de socaire para disipar la imposición de un conjunto de cargas mínimas, que es lo justo que se puede reclamar a quienes como servidores públicos se encargan de administrar el erario y de atender el interés general presente en tales empresas, que es lo que, en el fondo, legitima su existencia.

Bajo ese propósito, la Ley 1150 de 2007, consciente de que la administración pública no es una estructura homogénea, sino, antes bien, un cuadro complejo de órganos situados con lógica distinta, que se traduce en regímenes de contratación especial, reconoció en todo caso que la contratación de todas las entidades estatales, al margen de la finalidad que persigan, se deben desarrollar "sin perder en ningún momento de vista el respeto a los principios rectores en la materia, básicamente a los de estirpe constitucional" (Santofimio, 2009a, p. 24).

Ese propósito se hizo evidente en los proyectos de ley que antecedieron a la expedición de la Ley $1150,{ }^{28}$ y en especial, en la posición del Gobierno nacional en torno a la reforma de la Ley 80 de 1993. Postura que tuvo como fundamento los documentos Conpes 3186 de 2002 y 3249 de 2003, en cuya página 11 de este último se dijo lo siguiente:

Reconociendo que algunas entidades, por la naturaleza de sus actividades industriales, comerciales y financieras, deben manejar reglas que escapan de la órbita de lo público, la ley deberá ordenar la observancia en su actividad contractual, de los principios de la función administrativa a que se refiere el artículo 209 de la Constitución Política (igualdad, moralidad, eficacia, economía, celeridad, imparcialidad y publicidad), así como el de selección objetiva, con el objeto de garantizar la transparencia e idoneidad en la escogencia de los contratistas.

27. Sobre el particular, Villar Palasí (1950) de tiempo atrás anotaba que la administración, al “inmiscuir su actividad (...) en una posición de prepotencia ostensible, daría lugar a formación monopolística del mercado, disminuyéndose el incentivo empresarial del particular por la acumulación de obstáculos que se le opondrían al enfrentarse con concurrencia más potente que él, no solo financieramente, sino más bien por los privilegios del mercado inherente al imperium" (p. 95). Ese pensamiento, por ejemplo, es el que ha motivado a la redacción del inciso segundo del artículo 87 de la Ley 489 de 1998, según el cual, “las empresas industriales y comerciales del Estado, que por razón de su objeto compitan con empresas privadas, no podrán ejercer aquellas prerrogativas y privilegios que impliquen menoscabo de los principios de igualdad y de libre competencia frente a las empresas privadas".

28. Proyectos de ley número 07 de 2003 y 35 de 2004. 
Fue así como el artículo 13 de la Ley 1150 de 2007 estableció que todas las entidades estatales que por disposición legal cuenten con un régimen contractual excepcional al del estatuto general de contratación, aplicarían, en desarrollo de su actividad contractual, los principios de la función administrativa y de la gestión fiscal de que tratan los artículos 209 y 267 de la Constitución Política, como el régimen de inhabilidades e incompatibilidades previsto legalmente para la contratación estatal.

Empero, huelga subrayar que la expedición del artículo 13 ibídem no resultó ser, en sí misma, algo novedoso en la materia, pues no hizo más que recoger, a través de una ley formal, lo que la doctrina ${ }^{29}$ y la jurisprudencia ${ }^{30}$ ya habían denunciado, esto es, que la adopción de regímenes excepcionales a la Ley 80 de 1993 no implicaba, para estas entidades estatales, el desconocimiento de los principios constitucionales, en especial, los de la función administrativa. Posturas que a su vez tenían como fundamento la misma Constitución, la cual, amén de su valor normativo inmediato y directo, comunica toda la interpretación y aplicación del andamiaje infraconstitucional. ${ }^{31}$
En todo caso, a la aludida ley no se le resta mérito, por cuanto como fuente de derecho tuvo la virtualidad de reafirmar una postura constitucional con el inequívoco propósito de proyectarlo en la práctica jurídica contractual.

Ahora bien, ¿qué significa que las entidades estatales prestadoras de servicios públicos domiciliarios se rijan en materia de contratación por los principios de la función administrativa? Antes que nada, es de anotar que la constitucionalización de los principios de la función administrativa es el resultado de la adopción, en el máximo nivel normativo, de aquellos principios rectores que informan las actuaciones y procedimientos administrativos diseñados, en otrora, por la Ley 58 de 1958 y el Decreto 01 de 1984, y que ahora se encuentran recogidos en la Ley 1437 de 2011.

Más allá de la dispersión de significados que los principios jurídicos ostentan en el derecho, ${ }^{32}$ y en atención a los precedentes normativos expuestos en el párrafo anterior, los principios de la función administrativa pueden entenderse como los parámetros deontológicos hacia los cuales debe orientarse la actuación administrativa. En tal sentido, fungen como pautas de

29. Al respecto: Santofimio Gamboa (2000, p. 60).

30. Corte Constitucional (Sentencia C-327 de 1999, C. Gaviria); Consejo de Estado (Consulta, 6 abr. 2000, F. Rodríguez).

31. Como bien lo afirma García de Enterría (1985) en una obra ya clásica, "la Constitución constituye el "contexto" necesario de todas y cada una de las Leyes y Reglamentos y normas del ordenamiento a efectos de su interpretación y aplicación, aunque sea un contexto que a todas las excede en significado y rango" (p. 102).

32. Para Otero Parga (2001, p. 79), los principios pueden entenderse 1) como una norma muy general; 2) como una norma redactada en términos particularmente vagos; 3) como norma programática o directriz; 4) como norma que expresa los valores superiores de un ordenamiento jurídico; y 5) como norma sobre la solución y la interpretación de las normas aplicables. 
interpretación y aplicación de las instituciones que componen el iter contractual de las entidades estatales. Se trata, entonces, de auténticas normas jurídicas, por lo que los órganos públicos no deben entenderlas como meros estándares retóricos sin ningún tipo de peso en la realidad jurídico-práctica. Tan es así, que la inaplicación de dichos principios puede dar lugar al adelantamiento de investigaciones de carácter fiscal, disciplinario, penal e, incluso, comprometer la responsabilidad patrimonial del Estado.

Con todo, considero que su mera enunciación en las normas jurídicas no es suficiente, toda vez que su textura abierta ${ }^{33}$ dificulta su materialización en la praxis jurídica, lo cual enerva, de cierto modo, su eficacia. ${ }^{34}$ De ahí, pues, la necesidad de que sean recogidos por reglas ${ }^{35}$ a efectos de darles vida concreta en la dinámica jurídica, vale decir, para hacerlos plenamente operativos.
Un ejemplo claro de la recepción de los principios de la función administrativa por normas jurídicas organizadas a modo de reglas, se encuentra en los procedimientos administrativos generales que instrumenta la Ley 1437 de 2011; así mismo, se hallan en los procedimientos administrativos especiales que recogen la misma Ley 80 de 1993 y la Ley 1150 de 2007 relativa a la etapa precontractual de escogencia de los contratistas.

La cuestión está en determinar la manera como estos principios operan en relación con los contratos que celebran las empresas de servicios públicos domiciliarios. El artículo 13 de la Ley 1150 de 2007 solo se limitó a decir que estas empresas deberán atender los principios de la función administrativa en su contratación, mas no diseñó la forma como estos serán instrumentados, lo cual dificulta, como se acotó, su dinámica jurídica en la práctica. ${ }^{36}$

33. En virtud de la textura abierta que revisten los principios jurídicos, Leguina Villa (1987), apoyándose en un célebre autor, afirmaba que los principios pueden entenderse "como normas sin supuesto de hecho concreto, en cuanto que son una "mezcla de precisión" (que evita su disolución nebulosa) e indeterminación (que permite su dinamicidad y su superioridad de grado para dominar supuestos muy varios) (García de Enterría), sin llegar por sí mismos a suministrar decisiones a los casos concretos" (p. 11).

34. Es por ello que la Corte Constitucional (Sentencia T-406 de 1992, C. Angarita) expresa que los principios, a pesar de "poseer valor normativo, siguen teniendo un carácter general y por lo tanto una textura abierta, lo cual, en ocasiones, limita la eficacia directa de los mismos. En estos casos se trata de un problema relativo a la eficacia más o menos directa de los principios y no a un asunto relacionado con su falta de fuerza normativa".

35. Las reglas son -como lo sostiene la doctrina- normas jurídicas provistas de una "estructura condicional hipotética". Operan, pues, a modo de disyuntiva o dentro de un esquema de "todo o nada"; de suerte que cumplidas las condiciones contenidas en los "supuestos de hecho" señaladas en las reglas, le siguen, necesariamente, las "consecuencias jurídicas" previstas en él. De ahí que si "Ios hechos que estipulan una norma están dados, entonces o bien la norma es válida, en cuyo caso la respuesta que da debe ser aceptada, o bien no lo es, y entonces no aporta nada a la decisión” (Dworking, 2002, p. 75).

36. Al respecto, el profesor David Suárez (2010) manifestaba, en relación con lo dispuesto en el artículo 13 de la Ley 1150 de 2007, que "la absoluta generalidad de los principios de la función pública-administrativa y de la gestión fiscal, entendida en sentido amplio, dificulta la determinación de contenidos específicos en la actividad contractual cotidiana de los entes no sometidos al estatuto general de la contratación estatal" (p. 221). 
Pues bien, merced a dicho silencio, y ante la constatación inequívoca de que los principios de la función administrativa informan de manera transversal toda la gestión contractual que adelantan las empresas públicas de servicios públicos domiciliarios, huelga decir, todo el proceso de "adjudicación, celebración de contratos, ejecución y, de ser el caso, de liquidación" (Santofimio, 2009a, p. 34), se tiene que una manera de hacerlos operativos es, precisamente, a través de la adopción de los manuales o estatutos de contratación que elaboran dichas empresas, toda vez que el derecho común carece de procedimientos reglados para su concreción.

En ese sentido, los manuales de contratación son y serán los documentos que garanticen los principios de la función administrativa, entre otros, los de igualdad, moralidad, eficacia, economía, celeridad, imparcialidad, publicidad, transparencia, eficiencia, planeación, selección objetiva, ${ }^{37}$ libre concurrencia y contradicción. ${ }^{38}$ Principios que deberán estar organizados en las actividades de planeación, coordinación, organización, control, ejecución y supervisión de los procesos de contratación por ellas desplegadas.

Aspecto de vital importancia en la adopción de estos manuales de contratación será el relati- vo a los procedimientos de selección de contratistas. En ellos se deberán establecer los cauces por medio de los cuales participarán los oferentes interesados en celebrar negocios jurídicos con las empresas de servicios públicos, esto es, las modalidades de selección de contratistas, y como corolario de lo anterior, la determinación de los plazos, los criterios y factores de evaluación y calificación de las propuestas; los criterios de desempate; las garantías y, en general, los demás aspectos que garanticen el cumplimiento de los principios y objetivos misionales de la empresa.

De hecho, a propósito de las modalidades de selección de contratistas, considero que la mejor manera en que se cumplen y desarrollan los principios de la función administrativa en la etapa de formación contractual es a través de los mecanismos de participación plural, esto es, en los que se logra optimizar o estimular la mayor concurrencia de oferentes. De allí se concluye que estos procedimientos deben ser la regla general, y, correlativamente, la selección directa, la excepción. Esto significa que en los manuales de contratación debe estar plenamente justificado por qué una causal de contratación se subsume en una u otra modalidad de selección, ya sea por la naturaleza del objeto a contratar, la cuantía del bien o servicio a adquirir, circunstancias del mercado, aspec-

37. Para el profesor Juan Carlos Expósito (2009, p. 138), la selección objetiva no es propiamente un principio sino un deber. Dicha tesis la soporta, a su vez, en la aproximación conceptual elaborada por Robert Alexy, quien entiende a los principios como mandatos de optimización. Sin embargo, creo que la selección objetiva sí se puede considerar como un principio si se la mira como un principio en estricto sentido, en la terminología de Manuel Atienza y Ruiz Manero (2005).

38. Comparto la tesis del profesor David Suárez (2010, p. 220), en el sentido que los principios de la función administrativa no se agotan en los enunciados en el artículo 209 de la Constitución, sino también en todos aquellos postulados de la función administrativa que componen el contenido social y democrático del Estado de derecho. 
tos de confidencialidad o supuestos estratégicos que hagan necesaria una especial agilidad en la contratación para aprovechar una oportunidad de negocio, entre otros (CE Contencioso, 29 Jul. 2013, D. Rojas).

Esta tesis encuentra soporte jurídico, por demás, en virtud del mismo complejo normativo previsto en la Ley 142 de 1994. Así, el Consejo de Estado, en sentencia del 2 de diciembre de 2013 (Sección 3, S. Conto), determinó que los principios de libre iniciativa y competencia económica, transparencia, neutralidad y prestación eficiente, son pautas de interpretación de las normas que rigen la contratación de las prestadoras de los servicios públicos domiciliarios por virtud de la remisión que hace el artículo 30 ibídem. ${ }^{39}$ De esta suerte, las empresas, en la adquisición de bienes y servicios, cuando sea posible, habrán de utilizar mecanismos que aseguren la mayor concurrencia de oferentes, quienes deberán ser tratados en condiciones de igualdad. Medio idóneo que permite la optimización de los aludidos principios, de manera que su inobservancia puede acarrear, incluso, que el contrato así celebrado carezca de validez.
En todo caso, no se puede soslayar el contexto en que se desenvuelve la empresa pública en la prestación de estos servicios; de allí que la doctrina haya advertido que los procedimientos contractuales que adelantan estas entidades deben estar diseñados de tal manera que les permitan competir en igualdad de condiciones con los particulares, por lo que la intensidad de estos principios -o alguno de ellos- no se puede aplicar con el mismo rigor al que se exige a las entidades estatales disciplinadas por el estatuto general de contratación, ${ }^{40}$ de manera que dichos cauces procesales deben adecuarse a parámetros de eficiencia económica a través del diseño de mecanismos de selección que comprendan la realización de un análisis costo-beneficio. ${ }^{41} \mathrm{En}$ consecuencia, serán los órganos competentes de estas entidades estatales, generalmente sus juntas directivas, las encargadas de la difícil tarea -pero, a su vez, de la gran oportunidad- de conciliar o armonizar por medio de dichos estatutos los principios de la función administrativa frente a las exigencias de libre competencia que demandan los servicios públicos domiciliarios de acuerdo con la diná-

39. Los principios a que remite el artículo 30 de la Ley 142 de 1994, a propósito de la contratación, son, entre otros, los contenidos en los artículos $2^{\circ}$, numerales 2.5 (eficiencia) y 2.6 (libertad de competencia); $3^{\circ}$, numeral 3.9 (neutralidad) y 34 (igualdad), por cuanto la norma ordena que en los negocios jurídicos bilaterales que adelantan las empresas se "deben evitar privilegios y discriminaciones injustificados".

40. Al respecto Atehortúa (2010) señalaba, a propósito del alcance del artículo 13 de la Ley 1150 de 2007, "que la aplicación de los principios, no es mecánica, ni corresponde al régimen legal contenido en los artículos 23, 24, 25 y 27 de la Ley 80 de 1993, sino que la aplicación es "acorde con su régimen legal especial", lo que significa que en la aplicación de los principios debe hacerse una adecuación normativa en la cual se respete el núcleo esencial de cada principio, pero a su vez su interpretación y aplicación reconozca el régimen especial dentro del ámbito concreto en el que se está aplicando, que para el caso es el de los servicios públicos domiciliarios, que están sujetos a reglas de competencia y competitividad, propias de la apertura y la liberalización de los mismos" (p. 512).

41. Sobre el análisis económico de los procedimientos de selección de contratistas en el ámbito jurídico colombiano y la propuesta de un modelo de selección de contratistas eficiente puede verse Safar Díaz (2009). 
mica y las necesidades propias de la empresa pública que administran.

En ese sentido, los manuales de contratación pueden llegar a ser un buen anhelo de lo que proponen los juristas administrativistas para evitar aquella preocupación derivada de eso que se ha denominado la huida del derecho administrativo. Es decir, la aplicación de un derecho administrativo moderno, "desprovisto de formalismos excesivos, y dispuesto, desde su mismo diseño, a facilitar las exigencias de una administración moderna, volcada a la competencia con los particulares", permitiendo al administrador público "actuar con seguridad, eficacia y eficiencia” (Marín Cortés, 2006, p. 82).

Finalmente, se tiene que estos manuales de contratación son, según el Consejo de Estado, verdaderos actos administrativos que emanan de la facultad que les otorga el artículo 32 de la Ley 142 de 1994 para dictar todos aquellos "actos necesarios para su administración". Fundamento normativo que las habilita para establecer las reglas contractuales para la “adquisición de bienes y/o servicios que requieran para el cumplimiento de su objeto social". ${ }^{42}$
Al gozar, pues, dichos manuales de esa naturaleza jurídica, es fácil concluir que de ello se derivan varias consecuencias, que no son otras que las que se desprenden, de un lado, de los elementos comunes de todo acto administrativo, y, de otro, de las especificidades que les son propias. Partiendo de lo anterior, se pueden establecer las siguientes características: i) son de estricto cumplimiento tanto para la empresa pública en el desarrollo de sus actos negociales como para los particulares que pretendan contratar con dicha empresa; ii) se presumen ajustados a derecho; iii) son pasibles de control jurisdiccional ante el juez contencioso administrativo; iv) son obligatorios mientras no hayan sido anulados o suspendidos por la jurisdicción contenciosa administrativa; v) son reglamentos administrativos, toda vez que tienen la virtualidad de innovar el ordenamiento, pues se aplican de manera indefinida en el tiempo por comprender situaciones de carácter general que no se agotan en un solo acto sino que, antes bien, se renuevan cada vez que se verifican los supuestos de hecho y de derecho previstos en ellos; y, vi) se expiden en el ejercicio de competencias discrecionales, habida cuenta que el legislador no predetermina la forma en que se deben estructurar; facultad que, en todo caso, debe desarrollarse de manera adecuada a los fines de la norma que la auto-

42. En efecto, sostuvo el Consejo de Estado en dicha ocasión que "es la propia Ley 142 la que faculta a las empresas públicas de servicios públicos domiciliarios a dictar todos los actos necesarios para su administración, en consecuencia, los manuales de contratación no son nada distinto que una manifestación de dicha competencia atribuida directamente por la ley, que, en virtud de su contenido material y el capital 100\% público de las empresas oficiales de servicios públicos domiciliarios, revisten la forma jurídica de actos administrativos de contenido general, sin que ello signifique que su régimen contractual sea el del derecho público pues, como se verá este solo se aplicará de manera excepcional" (13 abr. 2011, 0. Santofimio, p. 20). [Cursivas añadidas]. Nótese que dicha tesis aplica para las empresas oficiales; sin embargo, considero que ello no es óbice para que sea aplicable a las empresas industriales y comerciales del Estado y a las empresas de servicios públicos domiciliarios mixtas con capital público mayoritario. 
riza y proporcional a los hechos que le sirven de causa (art. 44, Ley 1437 de 2011).

En suma, como consecuencia de todo lo anterior, se concluye que en los contratos que adelantan las empresas públicas de servicios públicos domiciliarios impera una relativa administrativización o publicización de la normatividad que las disciplina. Pues si los principios de la función administrativa son el soporte estructural en que se asientan las reglas y procesos contractuales que ellas ejecutan, es claro que esta actividad se halla irradiada, impregnada, invadida o permeabilizada por el cuadro de valores que informan estos principios en virtud de su triple función de fundamento, interpretación e integración que esta clase de normas proyectan en un sistema jurídico. ${ }^{43}$ Luego, al igual que sucede con las entidades estatales regidas por el estatuto general de contratación, "las codificaciones comercial o civil se [aplican] al fenómeno negocial del Estado pero bajo el espíritu derivado de los principios públicos" (Santofimio, 2009b, p. 15), ${ }^{44}$ solo que en este caso su concreción opera por una suerte de autodisciplina reglamentaria, que son sus manuales de contratación. ${ }^{45}$

\section{Algunas limitaciones a la autonomía de la voluntad privada en la contratación de las empresas públicas con respecto a la prestación de servicios públicos domiciliarios}

La vigencia de la autonomía de la voluntad privada en la contratación estatal ${ }^{46}$ no está libre de reparos. La razón es clara merced al principio de legalidad que impera en las entidades estatales como corolario del Estado de derecho. Por ello se afirma, que mientras en el sector privado impera la noción de capacidad -que le permite hacer todo aquello que no le esté prohibido-, en el sector público impera la noción de competencia, dado que únicamente puede hacer lo que le está expresamente permitido (Palacio Hincapié, 2014, p. 86).

El tema adquiere mayor complejidad cuando se parte de la concomitancia de dos situacio-

43. “Los principios como lo reconoce la doctrina están llamados a cumplir en el sistema normativo los siguientes papeles primordiales: (i) Sirven de base y fundamento de todo el ordenamiento jurídico; (ii) actúan como directriz hermenéutica para la aplicación de las reglas jurídicas; y finalmente, (iii) en caso de insuficiencia normativa concreta y específica, se emplean como fuente integradora del derecho. En estos términos, es indiscutible que los principios cumplen una triple función de fundamento, interpretación e integración del orden jurídico" (CConst., C-818 de 2005, R. Escobar).

44. En ese mismo sentido, Marín Cortés (2010, pp. 345 y 360).

45. No debe entenderse, empero, que la aplicabilidad de los principios de la función administrativa penda de su recepción por parte de los reglamentos de contratación, pues así el estatuto de la empresa pública no los hubiere desarrollado en forma expresa o de acuerdo con el alcance que les ha brindado la ley, la jurisprudencia y la doctrina, estos continúan siendo, en todo caso, obligatorios en su actividad negocial y, por ende, plenamente fiscalizables por parte de los órganos de control y el juez del contrato.

46. Es constante la jurisprudencia del Consejo de Estado en el sentido que son contratos estatales todos los contratos que celebran las entidades públicas del Estado, ya sea que se regulen por la Ley 80 de 1993 o estén sujetos a regímenes especiales, como acontece en el presente caso. 
nes, a saber: por una parte, cuando el principio de legalidad está informado por el principio de vinculación positiva, según el cual la ley no solo actúa como límite sino también como habilitante expresa del actuar del Estado; y por otra parte, cuando ese principio intenta ser aplicado al Estado empresarial, el cual requiere de un amplio margen de libertad para adecuarse a los patrones dinámicos del mercado.

Esta situación fue advertida, en su momento, por Zagrebelsky (1995, p. 35), quien al examinar las características del Estado constitucional expresaba cómo la asunción de tareas de gestión directa de intereses públicos ha llevado a que los grandes aparatos organizativos públicos actúen "necesariamente según su propia lógica, determinada por reglas empresariales de eficiencia [y] exigencias objetivas de funcionamiento"; factor que ha producido la crisis de la predeterminación legislativa en la actuación de la administración.

No obstante lo anterior, se puede decir que la crisis del principio tradicional de legalidad en la gestión pública empresarial halla en el ejercicio de competencias discrecionales el punto de entronque que permite articular la exigencia de sujeción al orden jurídico con la necesidad de un espacio de libertad de actuación. Luego, se puede afirmar, que la autonomía de la voluntad en la contratación estatal aparece "cuando la ley autoriza a la administración a escoger libremente entre varias soluciones igualmente conformes a la legalidad a través del reconocimiento de un poder discrecional" (Benavides, 2004, p. 95). [Cursivas originales].

Ello sucede, justamente, con la contratación que adelantan las empresas públicas en la gestión de servicios públicos domiciliarios, pues es claro que estas entidades estatales gozan de una amplia y clara facultad discrecional para la estructuración de sus negocios jurídicos y, por ende, para definir su contenido. ${ }^{47}$ Discrecionalidad que no es sinónimo de capricho o liberalidad, ya que el ejercicio de estas facultades está sujeto al marco del derecho; marco que comprende, a su vez, las reglas y principios constitucionales, en especial los de la función administrativa y la gestión fiscal, la Ley 142 y 143 de 1994, la normatividad de las comisiones de regulación, la legislación civil y comercial, entre otros.

Es precisamente en virtud de ese complejo normativo que estas empresas encuentran barrera a una de las libertades contractuales básicas derivadas de la autonomía de la voluntad: la libertad de elegir a su contratista. ${ }^{48}$ En efecto, ello sucede no solo como consecuencia de las causales de inhabilidad e incompatibilidad de carácter constitucional y legal que limitan la capacidad contractual de los particulares, sino también debido a la particularidad de los principios de la función administrativa, ya que estos están enderezados a que la selección de los contratistas se realice a través de criterios objetivos, por lo que, salvo que exista

47. Sobre las potestades discrecionales en el contrato estatal puede verse Santofimio (2009b).

48. Sobre el particular, Suescún Melo (1995). 
una justificación para contratar directamente, la adjudicación debe estar precedida de procedimientos que estimulen la mayor concurrencia de oferentes con el inequívoco propósito de evitar privilegios o discriminaciones injustificadas, optimizar recursos y elegir la mejor oferta.

Ahora bien, es esa misma dinámica la que genera, a su turno, una proyección normativa hacia la configuración del contenido del negocio jurídico, que es otra de las libertades contractuales de la autonomía de la voluntad. Ciertamente, siendo la selección del contratista el resultado de un procedimiento plural, participativo y en competencia entre proponentes, es claro que el adjudicatario no puede desplazar hacia un tercero la ejecución material absoluta de las actividades que comprende el contrato, dado que la "subcontratación no puede generar el desconocimiento del procedimiento de selección del cual es producto y de sus principios orientadores" (Ramírez Grisales, 2012, p. 100), entre ellos, el de transparencia y selección objetiva. Por ello, será en los manuales de contratación, en las condiciones de la oferta o en el mismo contrato, en donde la empresa pública deberá entrar a regular este aspecto, fijando, en consecuencia, "un límite inferior y un límite superior, respecto del valor adjudicado, para la celebración de subcontratos" (Ramírez Grisales, 2012, p. 70).
A propósito de la configuración del contenido del negocio jurídico bilateral por parte de estas empresas públicas, habría que preguntarse si a ellas les está permitido, por ejemplo, declarar la terminación unilateral del contrato por el incumplimiento del contratista, haciendo abstracción de la hipótesis prevista en el inciso 2 del artículo 31 de la Ley 142 de 1994. Al respecto, téngase en cuenta que como consecuencia de la creciente irrupción del unilateralismo negocial, en el derecho privado se ha venido aceptando por virtud de la ley o autonomía de la voluntad poderes unilaterales en manos de los particulares. ${ }^{49}$ De manera reciente, la Corte Suprema de Justicia (Civil, 30 ago. 2011, W. Namén Vargas) ha anunciado una lista de ejemplos normativos que permiten a las partes crear y reconocerse poderes de esta naturaleza, poniendo de presente el rol que juega la autonomía privada en este campo. Sin embargo, la posición del Consejo de Estado (Sección 3, 16 feb. 2006, R. Saavedra Becerra; 15 nov. 2011, R. Correa Palacio; 20 feb. 2014, R. Pazos Guerrero) parece ser al contrario, pues apoyado en los artículos 6, 121 y 122 de la Constitución Política -que pregonan el principio de legalidad de la administración-, ha sostenido que a las entidades estatales regidas por el derecho común les está proscrito terminar unilateralmente los contratos por ellas celebrados ya que no existe habilitación legal expresa para ello, sometiéndola a limitaciones que no tienen los particulares..$^{50}$

49. Al respecto: Molina Morales (2006, 2009).

50. Me atrevería a decir que las empresas públicas pueden terminar unilateralmente sus contratos por fuera de la hipótesis prevista en el inicio 2 del artículo 31 de la Ley 142 de 1994, siempre y cuando sus negocios jurídicos se encuadren dentro de las autorizaciones que los códigos Civil y de Comercio consagran, pues en tal caso se está respetando el principio de legalidad en virtud de la habilitación expresa del legislador, solo que la autorización proviene del derecho común y no de una norma especial. 
Siguiendo con la línea argumentativa decantada párrafos más arriba, esto es, cuando un contrato es producto de un proceso de selección plural, se tiene que hay un límite a su modificación dado que este no puede alterar sus condiciones esenciales. Entendiéndose por mutaciones esenciales -siguiendo para tal efecto a la legislación española ${ }^{51}$ y a la jurisprudencia comunitaria-, ${ }^{52}$ aquel caso en que pueda presumirse que, de haber sido conocida previamente la modificación, hubiesen concurrido al procedimiento de adjudicación otros interesados, o que los oferentes que tomaron parte de este hubieran presentado otras sustancialmente diferentes a las formuladas. De lo contrario, se atentaría contra los principios de transparencia e igualdad.

En el mismo sentido, es forzoso anotar que al igual que ocurre con las entidades estatales regidas por la Ley 80 de 1993 (art. 40), las empresas públicas deben establecer expresamente en sus manuales de contratación el porcentaje máximo del precio que se puede adicionar durante la ejecución de los contratos por ellas celebrados, en razón, por ejemplo, de la modificación del precio básico unitario, por agregar algún elemento nuevo al alcance físico inicial del negocio jurídico o la extensión del plazo, pues, sin duda, de aceptar que estas pueden incrementar sin limitación alguna el valor del contrato, se terminaría por eludir, como lo admite la doctrina y la jurisprudencia, los procesos de selección determinados en sus estatutos.

Otro tanto ocurre con el plazo de ejecución -manifestación insigne de la autonomía privada-, toda vez que este no podría ser objeto, verbigracia, de prórrogas indiscriminadas o automáticas, ya que ello iría, en principio, en contra de los principios de libre concurrencia, igualdad, imparcialidad, transparencia (CE Consulta, 19 may. 2010, W. Zambrano) y planeación, ya que dicha práctica no solo reflejaría distinción de acceso a la contratación estatal hacia un reducido grupo de privilegiados, sino que también atentaría contra los principios presupuestales, en especial, el de anualidad.

En ese orden de ideas, se puede decir que los principios de la función administrativa, más allá de ser criterios orientadores de la contratación, pueden llegar a ser, inclusive, normas jurídicas de carácter imperativo que se explayan en los procedimientos de formación, celebración, ejecución y, de ser el caso, liquidación de los contratos de las empresas públicas de servicios públicos domiciliarios, dado que, amén de su carácter, enervan la libre disposición de estos, contrario a las normas de orden dispositivo. De suerte que por ser estos principios parte de la legalidad del negocio jurídico, su infracción puede acarrear hasta la nulidad absoluta del contrato, por objeto ilícito, que es uno de los remedios que prevé el orden jurídi-

51. Artículo 107 del Real Decreto Legislativo 3/2011, de 14 de noviembre, por el que se aprueba el texto refundido de la Ley de Contratos del Sector Público.

52. Sentencia del Tribunal de las Comunidades Europeas (STJCE), 13 abr. 2010, asunto C-91/98 (caso Wall AG). 
co para paliar la violación a las normas imperativas ${ }^{53} \mathrm{o}$ de orden público cuyo asidero jurídico se halla en los artículos 6, 16, 1518, 1519, 1524 y 1741 del Código Civil y 899 del Código de Comercio.

Esta tesis, a propósito, encuentra apoyatura en reciente práctica judicial del Consejo de Estado. Así, en tratándose del principio de planeación, se ha construido una suerte de línea jurisprudencial cuando se transgrede gravemente dicho principio en la formación del contrato estatal, derivándose la sanción de la nulidad absoluta del contrato (CE Sección 3, 24 abr. 2013; 13 jun. 2013; 2 oct. 2014, 0. Santofimio).

Así mismo, en otra ocasión, dicha Corporación declaró la nulidad absoluta de un contrato celebrado por una entidad estatal para la prestación de servicios públicos domiciliarios por contravenir los principios constitucionales y legales. En particular, se le reprochó el hecho de que hubiera adjudicado un contrato de manera directa cuando lo cierto era que se trataba de un bien disponible abiertamente en el mercado, debilitando, de este modo, la libre concurrencia al proceso para garantizar la imparcialidad y la transparencia en la selección de proponentes dentro del marco de condiciones objetivas con miras a la prestación eficiente del servicio (CE Sección 3, 02 dic. 2013, S. Conto).

Desde luego, no cualquier transgresión a los principios de la función administrativa da lugar, inexorablemente, a la sanción de la nulidad absoluta del contrato, ya que el grado de su vigencia depende, en gran parte, de la naturaleza del procedimiento de selección de contratistas aplicable. Será, pues, en cada caso, donde se entre a valorar el nivel de infracción de estos principios de acuerdo con las circunstancias que la rodean a efectos de discernir si son requisitos legales esenciales de indiscutida observancia. ${ }^{54}$

\section{CONCLUSIONES}

La connotación económica de los servicios públicos domiciliarios, como corolario de la liberalización que significó la Constitución Política de 1991, trajo aparejado el discurso -sin perjuicio de algunas leves diferencias- de la homogeneidad del régimen jurídico de las empresas públicas y privadas en virtud de las tesis de la igualdad y libre competencia que deman-

53. Sobre las normas imperativas y su proyección en la validez del contrato, el Consejo de Estado ha dicho que estas no son "solamente aquellas que prohíben sino también las que mandan u ordenan y por ende la transgresión del orden público se presenta cuando se viola la que prohíbe así como cuando no se observa o se desatiende la que ordena, casos todos estos que conducen a la nulidad absoluta por objeto ilícito" (...). // Así que no es cierto que para que un acto o contrato sea absolutamente nulo por objeto ilícito es indispensable la existencia de una norma que diga, expresa y sacramentalmente que "es nulo", como consecuencia, el acto que la contraviene, pero desde luego lo que sí debe existir es la norma que expresamente mande o prohíba" (Sección 3, 2 oct. 2014, O. Santofimio).

54. El orden público, según la jurisprudencia administrativa, “debe ser definido, en cada caso, por el juez de conocimiento, pues es un concepto que se enriquece y varía en el tiempo según las circunstancias” (CE Sección 3, 23 feb. 2000, G. Rodríguez). 
dan unas mismas reglas de juego a la hora de competir en el mercado.

Esa unificación jurídica, de algún modo, se debía reflejar, entre otros, en una de las actividades que con mayor calado impactan en el quehacer empresarial: el régimen de contratación, que por tratarse de una actividad en concurrencia tenía que ser el derecho privado.

La cuestión es que, tal como se pudo valorar en el presente trabajo, el discurrir jurídico por el que ha tenido que atravesar el régimen de contratación de las empresas públicas en la prestación de servicios públicos domiciliarios no se limita, a diferencia de los particulares, a unos cuantos controles instruidos por principios de control fiscal en razón de la presencia de capital público. Se trata, antes bien, de una auténtica dosificación de la legislación civil y comercial como consecuencia del espíritu informador de los principios de la función administrativa.

Ciertamente, las empresas públicas están obligadas a estructurar su actividad negocial de manera acuciosa y deliberada, bajo parámetros estrictos de planeación en la etapa de formación contractual; la selección de su contratista no es libre o caprichosa, sino objetiva y transparente a fin de evitar privilegios y discriminaciones injustificadas, lo cual demanda, las más de las veces, que la adjudicación de sus contratos esté precedida por procedimientos que estimulen la mayor concurrencia de oferentes; y correlativamente a lo anterior, les está proscrito, entre otras cosas, subcontratar absolutamente, realizar modificaciones sustanciales al objeto del acuerdo bilateral, adicionar ilimitadamente el valor del contrato y prorrogar el plazo de manera indiscriminada o automática.

Si bien estos puntos son solo algunos de los relativos a todo el complejo universo de la contratación, ${ }^{55}$ no es menos cierto que son suficientes para concluir que el régimen de derecho privado que impera en el sector público no es el mismo que el que predomina en el sector privado. Sin duda, los principios de la función administrativa - utilizando la terminología de Rivero (2002) - operan como una suerte de derogatorias "en menos", por cuanto dichas normas jurídicas le niegan a las empresas públicas las mismas posibilidades jurídicas que están a disposición de los particulares.

El anterior entendimiento no obedece a una mera liberalidad. Se trata de una interpretación que mira a la empresa pública como parte de la organización administrativa y de actividades generales del Estado, lo cual la hace tributaria de unos mínimos resortes de derecho público de carácter constitucional y legal. Luego, se puede afirmar que la acción estatal empresarial "responde a una lógica distinta no siempre compatible o en armonía con la lógica

55. No fueron objeto de análisis en el presente trabajo aspectos importantes como la influencia de las normas presupuestales en el régimen de contratación, las cargas tributarias especiales a las que son sometidas o las restricciones contractuales derivadas de la ley de garantías electorales. 
de la empresa privada" (Tafur, 1999, p. 450). ${ }^{56}$ De ahí que se pueda advertir una cierta tensión entre el respeto a principios de orden público y pretensiones de flexibilidad propias de la apertura y liberalización de los servicios públicos domiciliarios; tensión que, por lo pronto, los manuales de contratación están llamados a zanjar.

Tarea que, desde luego, no es nada fácil, debido a la complejidad de su régimen jurídico, lo cual se ve reflejado en la disparidad normativa de cada uno de los manuales de contratación adoptados por las distintas entidades estatales prestadoras de servicios públicos domiciliarios. Por ello, algún sector de la doctrina ha denunciado la inutilidad de los regímenes excepcionales, abogando por la universalidad del estatuto general de contratación, sin perjuicio de las modificaciones pertinentes a fin de que este pueda calar las exigencias de la empresa pública (Benavides, 2014; Jojoa, 2012; Dávila, 2016).

\section{Referencias}

1. Ariño Ortiz, G. (2003). Principios de derecho público económico. Bogotá: Universidad Externado de Colombia.

2. Atehortúa Ríos, C. A. (2008). Régimen de Ios servicios públicos domiciliarios: en el contexto de la doctrina constitucional. Medellín: Biblioteca Jurídica Diké.
3. Atehortúa Ríos, C. A. (2009). El régimen contractual en el sector de los servicios públicos domiciliarios. En J. O. Santofimio y J. L. Benavides (Comps.), Contratación estatal. Estudios sobre la reforma del estatuto contractual. Ley 1150 de 2007 (págs. 408-452). Bogotá: Universidad Externado de Colombia.

4. Atehortúa Ríos, C. A. (2010). Contratación de empresas estatales en sector de los servicios públicos. En Temas en Contratos Estatales (págs. 491-543). Medellín: Biblioteca Jurídica Diké.

5. Atienza, M. y Ruiz Manero, J. (2005). Las piezas del derecho: teoría de los enunciados jurídicos. Barcelona: Ariel.

6. Bassols Coma, M. (1977). Servicio público y empresa pública: reflexiones sobre las llamadas sociedades estatales. Revista de Administración Pública, (84), 27-59.

7. Benavides, J. L. (2004). El contrato estatal. Entre el derecho público y el derecho privado. Bogotá: Universidad Externado de Colombia.

8. Benavides, J. L. (2014). Contratos públicos: estudios. Bogotá: Universidad Externado de Colombia.

56. Es que, como lo afirma Dávila Vinueza (2016, p. 17): ahí “donde exista el Estado y se manejen recursos públicos, pretender la aplicación a ultranza del derecho privado resulta imposible. Como mínimo deben desarrollarse mandatos elementales que se originan en la preeminencia del interés público". 
9. Bernal Pulido, C. (2009). El neoconstitucionalismo y la normatividad del derecho: escritos de derecho constitucional y filosofía del derecho. Bogotá: Universidad Externado de Colombia.

10. Brewer Carías, A.-R. (1967). Las empresas públicas en el derecho comparado: estudio sobre el régimen de las actividades industriales y comerciales del Estado. Caracas: Universidad Central de Venezuela.

11. Carro Fernández-Valmayor, J. L. (2014). Reflexiones sobre las transformaciones actuales del derecho público, en especial del derecho administrativo. Revista de Administración Pública, (193), 11-44.

12. Cassagne, J. C. (2002). Evolución de los principios aplicables a los servicios públicos y problemas actuales tras el proceso de privatización. Revista de Administración Pública, (157), 467-494.

13. Correa Henao, M. (2008). Libertad de empresa en el Estado social de derecho. Bogotá: Universidad Externado de Colombia.

14. Dávila Vinueza, L. G. (2016). Régimen jurídico de la contratación estatal. Bogotá: Legis.

15. Dworkin, R. (2002). Los derechos en serio. Barcelona: Ariel.

16. Expósito Vélez, J. C. (2009). Contratación estatal. Estudios sobre la reforma del esta- tuto contractual. Ley 1150 de 2007. Bogotá: Universidad Externado de Colombia.

17. Fernández, T.-R. (1999). Del servicio público a la liberalización desde 1950 hasta hoy. Revista de Administración Pública, (150), 57-74.

18. Fernández-Miranda Campoamor, A. (2003). El Estado social. Revista Española de Derecho Constitucional, (10), 139-180.

19. García de Enterría, E. (1985). La Constitución como norma y el Tribunal Constitucional. Madrid: Thomson Civitas.

20. Garrido Falla, F. (Septiembre-diciembre de 1991). Privatización y reprivatización. Revista de Administración Pública, (126), 7-26.

21. Garrido Falla, F. (Septiembre-diciembre de 1994). El concepto de servicio público en el derecho español. Revista de Administración Pública, (135), 7-36.

22. Jezé, G. (1948). Principios generales de derecho administrativo. Buenos Aires: Depalma.

23. Jojoa Bolaños, A. (2012). Los regímenes exceptuados en los contratos estatales. Bogotá: Grupo Editorial Ibáñez.

24. Leguina Villa, J. (1987). Principios generales del derecho y Constitución. Revista de Administración Pública, (114), 7-37. 
25. Marín Cortés, F. (2006). La contratación de las empresas de SPD. Evaluación del tema y perspectivas legislativas. Letras Jurídicas, 11(1), 63-98.

26. Marín Cortés, F. (2010). Los servicios semipúblicos domiciliarios. Bogotá: Temis.

27. Molina Morales, R. (2006). La terminación unilateral del contrato ad nutum. Revista de Derecho Privado, (10), 125-158.

28. Molina Morales, R. (2009). La terminación unilateral del contrato por incumplimiento. Revista de Derecho Privado, (17), 77-105.

29. Montaña Plata, A. (2003). Alcances de la libertad económica privada en el régimen de servicios públicos introducidos por la Constitución Política de 1991. Revista de Derecho del Estado, 197-210.

30. Montaña Plata, A. (2005). El concepto de servicio público en el derecho administrativo. Bogotá: Universidad Externado de Colombia.

31. Montaña Plata, A. (Segundo semestre de 2009). La desconfiguración del régimen jurídico de los servicios públicos domiciliarios a partir de la calificación de entidades públicas a las empresas de servicios públicos mixtas. Revista Digital de Derecho Administrativo, (3), 163-190.

32. Montaña Plata, A. (2010). Fundamentos de derecho administrativo. Bogotá: Universidad Externado de Colombia.
33. Orozco Guerrero, O. (2009). El fin de la nueva gerencia pública. Revista Chilena de Administración Pública, (13), 6-22.

34. Otero Parga, M. (2001). Las fuentes del derecho. México, D. F.: Universidad Nacional Autónoma de México.

35. Palacio Hincapié, J. A. (2014). La contratación de las entidades estatales (Séptima ed.). Medellín: Librería Jurídica Sánchez R. Ltda.

36. Parada Vázquez, R. (2007). Derecho Administrativo I. Parte General. (Decimosexta ed.). Barcelona: Marcial Pons.

37. Palacios Mejía, H. (1999). El derecho de los servicios públicos. Bogotá: Derecho Vigente.

38. Ramírez Grisales, R. S. (2012). La subcontratación. Medellín: Librería Jurídica Sánchez R. Ltda.

39. Restrepo Medina, M. A. (2007). La respuesta del derecho administrativo a las transformaciones recientes del Estado social de derecho. Revista de estudios jurídicos, económicos y sociales, (5). Obtenido de: http://www.uax.es/publicacion/ la-respuesta-del-derecho-administrativo-alas-transfor macionesrecientes.pdf.

40. Restrepo Medina, M. A. (2010). Globalización del derecho administrativo colombiano. Bogotá: Universidad del Rosario. 
41. Rivero Ysern, E. (1978). Derecho público y derecho privado en la organización y actividad de las empresas públicas. Revista de Administración Pública, (86), 11-52.

42. Rivero, J. (2002). Páginas de derecho administrativo: libro homenaje. (H. G. Duque, Trad.). Bogotá: Temis/Universidad del Rosario.

43. Ruiz, F. J. (1982). El Estado empresario. México, D. F.: Universidad Nacional Autónoma de México, Instituto de Investigaciones Jurídicas.

44. Safar Díaz, M. S. (2009). Análisis económico de los procedimientos de selección de contratistas del Estado en el derecho colombiano: hacia un mecanismo eficiente $y$ transparente. Bogotá: Universidad Externado de Colombia.

45. Santofimio Gamboa, J. O. (2000). Delitos de celebración indebida de contratos: análisis con fundamento en la teoría general del contrato estatal. Bogotá: Universidad Externado de Colombia.

46. Santofimio Gamboa, J. O. (2009a). Aspectos relevantes de la reciente reforma a la Ley 80 de 1993 y su impacto en los principios rectores de la contratación pública. En J. O. Santofimio y J. L. Benavides (Comps.), Contratación estatal. Estudios sobre la reforma del estatuto contractual. Ley 1150 de 2007 (págs. 14-97). Bogotá: Universidad Externado de Colombia.

47. Santofimio Gamboa, J. O. (2009b). El carácter conmutativo y por regla general sinalagmático del contrato estatal y sus efectos respecto de la previsibilidad del riesgo y del mantenimiento de su equilibrio económico. Revista Digital de Derecho Administrativo, (1), 1-57.

48. Suárez, D. T. (2010). Huida o vigencia del derecho administrativo; el caso de los servicios públicos domiciliarios. Transformaciones-Tendencias del derecho administrativo. Medellín: Librería Jurídica Sánchez R. Ltda.

49. Suescún Melo, J. (1995). La aplicación del postulado de la autonomía de la voluntad en la contratación de las entidades estatales. Revista de Derecho Privado, (16), 9-57.

50. Tafur, Á. G. (1999). La huida de la administración hacia el privado en Colombia. En Derecho civil y comercial: doctrina (págs. 411-456). Medellín: Bliblioteca Jurídica Diké.

51. Villar Palasí, J. L. (Septiembre-diciembre de 1950). La actividad industrial del Estado en el derecho administrativo. Revista de Administración Pública, (3), 53-130.

52. Zagrebelsky, G. (1995). El derecho dúctil: ley, derechos, justicia (M. Gascón, Trad.). Madrid: Trotta. 